\title{
A study of the relationship between the quality of lifestyle counselling and later adherence to the lifestyle changes based on patients with stroke and TIA
}

\begin{tabular}{|c|c|}
\hline Journal: & Clinical Rehabilitation \\
\hline Manuscript ID & CRE-2016-5937.R3 \\
\hline Manuscript Type: & Original Article \\
\hline Keywords: & Stroke, counselling, health care quality, patient adherence, lifestyle \\
\hline Abstract: & 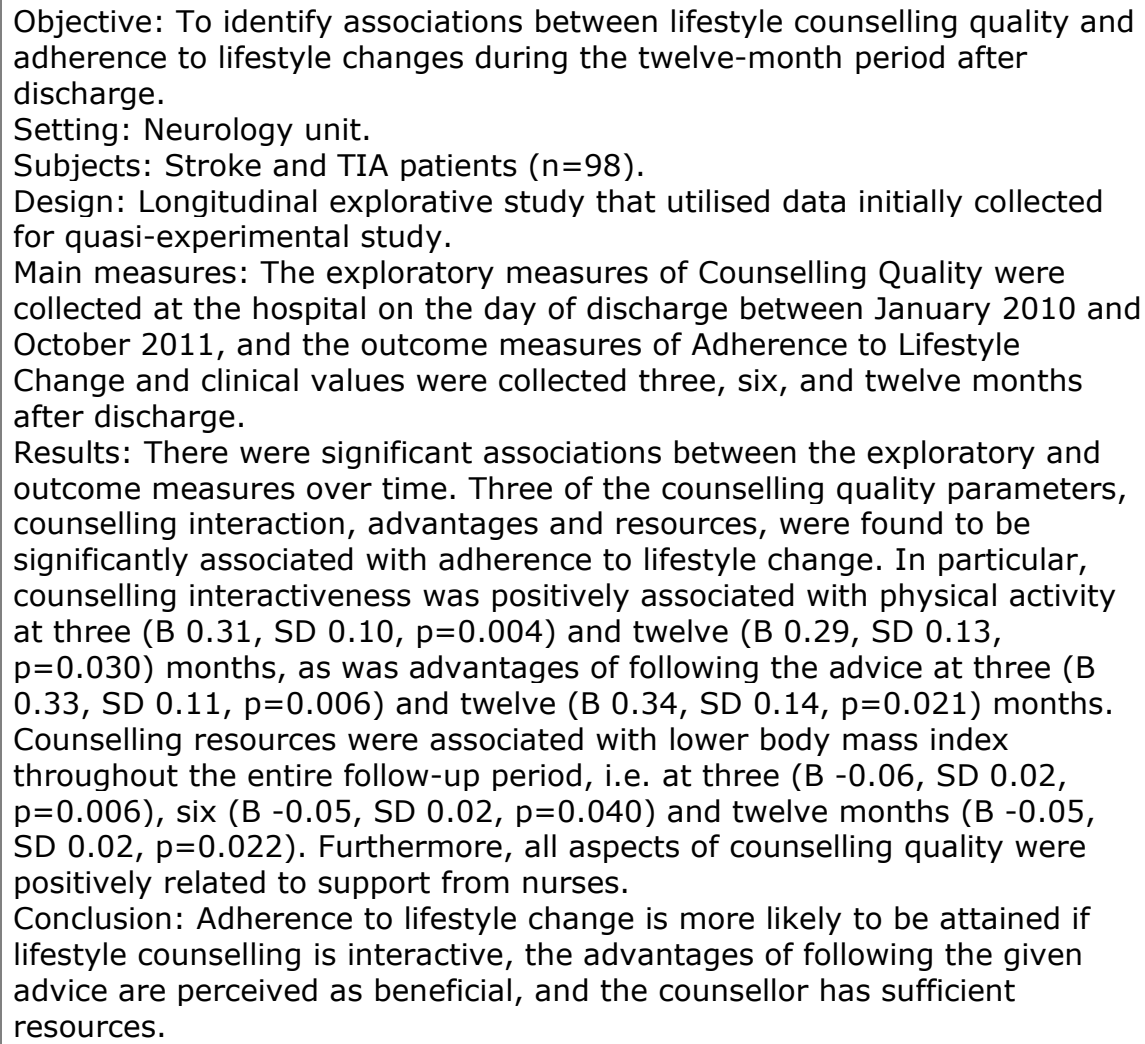 \\
\hline
\end{tabular}




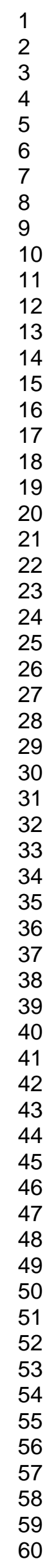

SCHOLARONE $^{\text {th }}$

Manuscripts

7

25

26

27

29

32

33

34

35

36

37

39

40

41

43

44

45

46

47

48

50

51

52

54

55

57

58

59

60

http://mc.manuscriptcentral.com/clinrehab 
Objective: To identify associations between lifestyle counselling quality and adherence to lifestyle changes during the twelve-month period after discharge.

Setting: Neurology unit.

Subjects: Stroke and TIA patients $(\mathrm{n}=98)$.

Design: Longitudinal explorative study that utilised data initially collected for quasi-experimental study.

Main measures: The exploratory measures of Counselling Quality were collected at the hospital on the day of discharge between January 2010 and October 2011, and the outcome measures of Adherence to Lifestyle Change and clinical values were collected three, six, and twelve months after discharge.

Results: There were significant associations between the exploratory and outcome measures over time. Three of the counselling quality parameters, counselling interaction, advantages and resources, were found to be significantly associated with adherence to lifestyle change. In particular, counselling interactiveness was positively associated with physical activity at three (B 0.31, SD 0.10, p=0.004) and twelve (B 0.29, SD 0.13, p=0.030) months, as was advantages of following the advice at three (B 0.33, SD 0.11, p=0.006) and twelve (B 0.34, SD 0.14, p=0.021) months. Counselling resources were associated with lower body mass index throughout the entire follow-up period, i.e. at three (B -0.06, SD 0.02, $p=0.006)$, six $(B-0.05$, SD 0.02, p=0.040) and twelve months (B -0.05, SD 0.02, $\mathrm{p}=0.022$ ). Furthermore, all aspects of counselling quality were positively related to support from nurses.

Conclusion: Adherence to lifestyle change is more likely to be attained if lifestyle counselling is interactive, the advantages of following the given advice are perceived as beneficial, and the counsellor has sufficient resources.

Keywords: counselling, health care quality, lifestyle, patient adherence, stroke, transient ischemic 


\section{INTRODUCTION}

In Finland, as well as in most other developed countries, legislation specifies the content of counselling provided at hospitals. ${ }^{1}$ Particularly, counselling about lifestyle-related risk factors plays a vitally important role. Successful counselling can impart significant beneficial changes to stroke patients' lifestyle habits and reduce the risk of new vascular events. $^{2,}$ 3-5 Therefore, more attention should be paid to both the delivery process and content quality of counselling. According to Kääriäinen ${ }^{6}$, counselling can be defined as good quality if the implementation of counselling is patient-centred, interactive and goal-oriented, if the counselling focuses on the advantages of following the advice given by the counsellor, and if the resources used are adequate. ${ }^{7-10}$

There is currently a lack of knowledge regarding the factors that predict good-quality counselling delivered to stroke patients or other chronically ill patients. However, patient-centred counselling is expected to provide better overall counselling quality and has been reported to be a strong predictor of positive outcomes although it has also repeatedly been proven to be one of the weakest aspects of counselling. ${ }^{10}$ Patientcentred counselling enables active participation in treatment and takes into account each patient's background factors, e.g. age, educational level and gender. The ideals of good counselling are unfortunately not always put into practice. 
Counselling that aims to help patients adhere to essential lifestyle changes should include information about strokes in general, behavioural lifestyle factors (e.g. diet, safe alcohol consumption, stress management, physical activity, smoking and weight control) and medication adherence. ${ }^{11-13}$ The concept of adherence refers to stroke patients adopting a responsible, active and intentional process of self-care in which they act to maintain their overall health in close co-operation with healthcare personnel. ${ }^{14-16}$ Earlier studies have confirmed that factors such as motivation, perceived importance of lifestyle change, and support from family, friends and hospital staff are connected to better adherence among patients with long-term illnesses. ${ }^{14-16}$

This study is a part of a larger project, the first phase of which examined how lifestyle intervention influences adherence to lifestyle change. ${ }^{15}$ The second phase aims to identify associations between the quality of lifestyle counselling for stroke and TIA (transient ischemic attack) patients received at the hospital and adherence to lifestyle changes during the twelve months following discharge. 


\section{METHODS}

This study used a longitudinal exploratory study design. ${ }^{17}$ The sample $(n=98)$ consisted of stroke and TIA patients who were treated in a neurological unit at a university hospital in Finland between January 2010 and October 2011. The patients were originally collected for a published quasi-experimental study. ${ }^{15}$ This data collection process included the gathering of data on lifestyle counselling quality on the day of discharge, which, along with follow-up data, serve as the basis for this study.

The research was conducted following permission from both the Nursing Committee and the Research Ethics Committee of the hospital (ETMK: 83 180/2009). The Code of Ethics of the World Medical Association (Declaration of Helsinki) was followed throughout the research process. Respondents received written and oral information on voluntary participation, data protection and confidentiality. The patients were given detailed information about the study and their ability to withdraw from the study at any time. Written informed consent was obtained from all participants. All the patients in the study received counselling during their hospital stay. However, it must be assumed that there was individual variation relating to both the hospital staff and stroke patients. Furthermore, counselling, even if it was to be standardised, must nevertheless be tuned to each individual patient's condition and circumstances. 
Patients were asked to participate in the study if they were diagnosed with either TIA or ischemic stroke, expected to be discharged, capable of giving informed consent and completing a questionnaire, and between 18 and 65 years of age. Patients that had a poor neurological status or could not communicate in Finnish were excluded from the study. The main researcher approached potential participants. The study design and flow of the participants during follow-up are presented in Figure 1.

Figure 1.

Following successful screening and informed consent, a total of 150 participants were recruited for the original study, of whom 98 (65.3\%) completed the Counselling Quality survey on the day of discharge from the hospital. Patients who completed the Counselling Quality survey were sent Adherence to Lifestyle Change Questionnaires at three, six and twelve months post-discharge to assess their adherence to lifestyle changes. The main researcher sent the follow-up surveys.

Furthermore, nearly half of the study participants $(n=45)$ received a lifestyle counselling intervention described in an earlier study. ${ }^{15}$ The study showed that the intervention does not significantly affect adherence to lifestyle change during the one-year follow-up period. For this reason, all of the participants in this study were considered as belonging 
to one group. However, the intervention was considered when analysing the data. This study paid particular attention to how the patients perceived the quality of counselling they received at the hospital, and its possible connection to adherence to a healthier lifestyle.

Exploratory measures: Lifestyle counselling quality was assessed by using the Counselling Quality Questionnaire. ${ }^{7-10}$ This questionnaire measures the content, implementation and resources of counselling along with the advantages of following the given advice. The participants responded to questions using a five-point Likert scale ranging from one (strong disagreement) to five (strong agreement). Both the validity and reliability of the questionnaire have previously been established, with the questionnaire showing good content and construct validity as well as good to excellent internal consistency based on Cronbach alpha values ranging from 0.8-0.9..$^{7-10}$

Outcome measures. The Adherence to Lifestyle Change Questionnaire ${ }^{15,16,18,19,20}$ was used to assess patients' adherence to lifestyle changes. This questionnaire includes multiple choice and dichotomous questions about lifestyle habits and clinical values, along with items about factors relating to adherence that are scored using a five-point Likert scale ranging from one (strong agreement) to five (strong disagreement). The 
validity and reliability of the questionnaire have previously been tested, with Cronbach's alpha values ranging from sufficient $(\alpha=0.40)$ to high $(\alpha=0.89) .{ }^{15,16,19}$

The data analysis used statistical tests and descriptive statistics that were performed in Statistical Analysis Software, version 9.2 (SAS Inc., Cary, USA). The questionnaire data included many variables that could influence the dependent variable. As per previous studies, ${ }^{10,15}$ a number of summated variables were created as a result of factor analysis. Certain variables, such as smoking (two items), weight control (two items), and stress management (one item), were not grouped with other variables. Table 1 shows the summated variables created and used in this study.

\section{Table 1.}

The analysis proceeded as follows. Repeated measures ANCOVA was used to examine associations between the quality of counselling and patients' lifestyle habits, clinical values, and factors related to lifestyle change adherence. Possible scores for each variable ranged from 1 to 100 , with higher scores indicating better quality of lifestyle counselling, a healthier lifestyle, and better adherence to lifestyle change. Associations were evaluated based on the ANCOVA estimates for regression slopes (B) and standard deviations (SD) between the sum variables. Regression slopes describe how a one 
percentage-point increase in the counselling variable affects the lifestyle variable in percentage-points. Associations between counselling quality variables and categorical lifestyle variables were analysed using multivariate ordinal logistic regression. Relationships between variables were characterised by calculating odds ratios (OR) and 95\% confidence intervals (CI).

The utilised study design includes a potential for bias because the outcomes may have been caused by factors that are extraneous to the research. Therefore, covariates such as age, experimental and control groups, sex, and education level were taken into account during the analyses. There were synergetic effects among the quality of counselling sum variables. Thus, after analysing the associations of the grouped counselling quality variables with adherence to lifestyle changes and related factors, their individual associations were also analysed, on which the results are based. During the data analysis phase, missing values were coded as blanks and complete case analysis was used in any cases of missing data during the follow-up. ${ }^{17}$ Incomplete patient datasets were incorporated in the analysis only if less than $25 \%$ of the sum variables items had missing values. Results were deemed significant if $\mathrm{p}<0.05$, and the results meeting this criterion are discussed. 


\section{RESULTS}

Stroke patients $(n=654)$ that had been admitted to the neurology unit were checked systematically. A total of 190 patients were identified as potentially eligible for the study. Forty of these patients declined to participate. Ninety-eight $(65.3 \%)$ of the original 150 patients who had provided written informed consent ${ }^{15,17}$ answered the Counselling Quality survey. Figure 1 presents the flow of the participants and Table 2 presents the background information of the study patients.

\section{Table 2.}

The statistically significant associations between counselling quality (exploratory variables) and lifestyle habits (outcome variables) are described in detail in Table 3. Repeated measures ANCOVA revealed that both good interaction in counselling and advantages of following the advice given by the counsellor associate with both better physical activity and healthier nutritional habits during the follow-up.

The data also showed that counselling resources are associated with better adherence to medication, lower body mass index (BMI) levels, smaller waist circumference and better physical activity. Moreover, as shown in Table 3, a multivariate ordinal logistic 
regression revealed that most of the counselling quality variables were significantly related to patients estimating themselves to be of normal weight twelve months after discharge.

Table 3.

Table 4 demonstrates the associations between counselling quality (exploratory variables) and adherence-related factors (outcome variables). Repeated measures ANCOVA revealed that all aspects of lifestyle counselling quality are positively related to a patient's perception of support from nurses three months after discharge. Most of the aspects of lifestyle counselling quality continue to positively influence a patient's perception of nurse support throughout the 12-month follow-up period. Interactiveness in counselling was associated with stroke patients having more motivation towards lifestyle change three months after discharge.

Table 4

Tables 3 and 4 also show that certain negative associations were detected six months following discharge. For example, patients estimated that their weight had increased or 
perceived less support from family, friends and doctors six months following discharge even though they had received good-quality counselling.

\section{DISCUSSION}

The results indicate that, in general, there seems to be an association between the quality of lifestyle counselling and adherence to lifestyle change over time. In particular, three of the counselling quality parameters - counselling interaction, advantages of following the given advice and counselling resources - seemed to be clearly associated with better adherence to lifestyle change. Furthermore, the findings indicate that a patient's rating of lifestyle counselling quality was in many ways related to perceived support from the nurses.

Good counselling interaction (e.g. encouraging, supporting, and providing an opportunity for feed-back in the counselling situation) was related to several aspects of lifestyle change adherence and various clinical parameters, including increased physical activity, healthier nutritional habits, probability of being of normal weight a year after discharge, and motivation at the beginning of post-stroke life. Some earlier studies have implicated a positive association between adherence to healthier lifestyle and good 
interaction in patient care, with most studies highlighting patient-doctor relationships ${ }^{21-}$ ${ }^{24}$ but some also emphasising nurse-patient relationships. ${ }^{25-26}$ Therefore, the pivotal role of counselling interaction should be highlighted when health care staff are provided basic and further education.

Additionally, the advantages of following the advice given by the counsellor (e.g. aiming to promote self-care, a positive attitude towards self-care and better knowledge about lifestyle-related risk factors) were connected to healthier nutritional habits and improved physical activity. This is consistent with prior research, which has found that patients who have good knowledge about their disease ${ }^{27}$, and who are more motivated to perform self-care and consider the results of care to be important are more likely to adhere to a healthy lifestyle. ${ }^{16,26}$

Furthermore, good counselling resources (e.g. availability of health care professionals' time and appropriate counselling materials, as well as the knowledge and skills of the nursing personnel) were associated with patients having a smaller waist circumference, increased physical activity levels and improved adherence to medication. They were also associated with lower BMI levels during the entire follow-up period. These results agree with previous findings that the delivery style of counselling relates to a patient's adherence. ${ }^{26-28}$ Thus, counselling truly challenges and demands health care staff to both 
teach and learn skills and work to absorb information about the learning styles of patients. Health literacy may also affect adherence and counselling quality based on how it influences a patient's understanding and desire to act on knowledge received from a health care professional ${ }^{29}$ Unfortunately, we were unable to examine health literacy in this study since no literacy measures were included.

The presented research highlights a special role for nurses in counselling patients and helping them to adhere to beneficial lifestyle changes since all of the counselling quality parameters were related to support from nurses (i.e. considering the life situation of the patient, motivating them in self-care and in lifestyle change). Previous studies have also found nurses' support to be a good predictor of adherence, ${ }^{18,19,28,30}$ although counselling is generally understood to be a joint responsibility of everyone participating in patient care at hospitals. ${ }^{31}$

It should also be noted that certain negative connections between the quality of counselling and adherence to lifestyle change were identified. Surprisingly, all of them were noticed at six months after discharge. For example, several counselling parameters were shown to be negatively related to perceived support from family and friends, as well as from doctors. According to previous research, patients who have survived stroke 
may experience problems with adherence at six months after discharge, ${ }^{15,32}$ a finding which may explain our findings.

We expected to find stronger associations between counselling quality and adherencerelated factors such as motivation and importance of lifestyle change. In contrast, our results suggest that counselling quality is not connected to most adherence-related factors. Confounding variables associated with both counselling and adherence may have contributed to this outcome even though we considered these effects by accounting for covariates in the analysis.

The results provide suggestions for stroke patient counselling in clinical hospital environments. This study identifies a need for training healthcare staff in diverse aspects of counselling and highlights that there is a connection between good-quality counselling and patients' adherence to healthier behaviour. Consequently, future studies should focus on these aspects, especially when the aim is to develop a lifestyle counselling programs that will improve stroke patients' adherence to a healthier lifestyle so that new strokes or other vascular events can be prevented.

However, the present study has several limitations. The representativeness of the sample causes some concern. This is because the sample size is relatively small and focused on 
a working age stroke group. For this reason, bias resulting from the non-reply rates during follow-up must be considered. One reminder questionnaire was sent during each phase of the data collection to enhance response rates.

Furthermore, all of the follow-up data were collected via self-reported questionnaires, a procedure that introduces well-known potential bias even if instruments with proven validity are used. Nevertheless, the study describes patients' perceptions of counselling quality, which is important to consider when developing lifestyle counselling.

The longitudinal exploratory study design also includes potential for bias because the outcomes may have been caused by factors that are extraneous to the scope of the research. This also applies to the fact that nearly half of the patients received the intervention, yet it was not effective enough to ensure long-term adherence to lifestyle change. Therefore, covariates were included in the presented analyses. As always, certain unmeasured confounders, such as fatigue and long-term symptoms, may exist. Nevertheless, this study provides an interesting view on the relationship between counselling and adherence.

Based on the aforementioned facts, the generalisation of the results should be approached with care. Thus, there is a clear need for further studies. However, our 


\begin{abstract}
results are consistent with findings from earlier studies that have investigated both adherence and counselling of patients with chronic illnesses. This indicates that the presented research may be widely applicable. One of the major strengths of this study is that it concerns a severe global health problem. Furthermore, despite recognition that lifestyle counselling quality and adherence to healthy lifestyle changes are both important for reducing the risk of stroke recurrence, the relationship between these two factors has not been studied until now.
\end{abstract}

\title{
Clinical message
}

- Lifestyle counselling by someone who interacts well with the patient, has sufficient time and knowledge to give correct information, and explains the advantages of following given advice is associated with greater change in lifestyle habits after stroke

- Support from nursing staff is associated with greater improvement in lifestyle

\section{Acknowledgements}

The authors would like to thank all of the patients who participated in the study, as well as the nursing staff and managers, for their assistance. 
16

\section{Funding statement}

This research did not receive any specific grant from the public funding agency, commercial, or not-for-profit sectors.

\section{Conflict of Interest Statement}

The authors declare that there is no conflict of interest. 


\section{REFERENCES}

1. Act 785/1992. Act on the Status and Rights of the Patients. http://www.finlex.fi/en/laki/kaannokset/1992/19920785 (1992, accessed 25 November 2016) [in Finnish].

2. Lennon S, McKenna S and Jones F. Self-management programmes for people post stroke: a systematic review. Clin Rehabil 2013; 27: 867-878.

3. Sit J, Yip V, Ko S, et al. A quasi-experimental study on a community-based stroke prevention programme for clients with minor stroke. J Clin Nurs 2007;16: 272-281.

4. Lawrence M, Kerr S, McVey C, et al. The effectiveness of secondary prevention lifestyle interventions designed to change lifestyle behavior following stroke: summary of a systematic review. Int J Stroke 2012; 7: 243247.

5. Lawrence M, Pringle J, Kerr S, et al. Multimodal secondary prevention behavioral interventions for TIA and stroke: a systematic review and metaanalysis. PLoS ONE 2015; 10: doi:10.1371/journal. pone.0120902.

6. Kääriäinen M. The Quality of Counseling: the Development of a Hypothetical Model. Doctoral dissertation, Oulu University Press, Oulu, 2007 [in Finnish].

7. Kääriäinen $M$ and Kyngäs $H$. The quality of patient education evaluated by the health personnel. Scand J Caring Sci 2010; 24: 548-556. 
8. Kääriäinen $M$, Kukkurainen $M$, Kyngäs $H$, et al. Improving the quality of rheumatoid arthritis patients' education using written information. Musculoskeletal Care 2011; 9: 19-24.

9. Kaakinen $P$, Kääriäinen $M$ and Kyngäs $H$. The chronically ill patients' quality of counselling in the hospital. J Nurs Educ Pract 2012; 2: 114-123.

10. Kaakinen $P$, Kyngäs $H$ and Kääriäinen $M$. Predictors of good-quality counselling from the perspective of hospitalised chronically ill adults. J Clin Nurs 2013; 22: 2704-2713.

11. Strong K, Mathers C and Bonita R. Preventing stroke: saving lives around the world. Lancet Neurol 2007; 6: 182-187.

12. O’Donnell D, Xavier D, Lui L, et al. Risk factors for ischaemic and intracerebral haemorrhagic stroke in 22 countries (the INTERSTROKE study): a case control study. Lancet 2010; 376: 112-123.

13. Kernan W, Ovbiagele B, Black H, et al. Guidelines for prevention of stroke in patients with ischaemic stroke and transient ischaemic attack: a guideline for healthcare professionals from the American Heart Association/American Stroke Association. Stroke 2014; 45: 2160-2136.

14. Kääriäinen $M$, Paukama $M$ and Kyngäs $H$. Adherence with health regimens of patients on warfarin therapy. J Clin Nurs 2013; 22: 89-96. 
15. Oikarinen A, Engblom J, Kääriäinen M, et al. The effects of Risk FactorTargeted Lifestyle Counselling Intervention on working-age stroke patients' adherence to lifestyle change. Scand J Caring Sci. 2016; doi: 10.1111/scs.12369. [Epub ahead of print].

16. Kähkönen O, Kankkunen P, Saaranen T, et al. Motivation is a crucial factor for adherence to a healthy lifestyle among people with coronary heart disease after percutaneous coronary intervention. $J$ Adv Nurs 2015; 71: 2364-2373.

17. Polit D and Beck C. Nursing Research: Generating and Assessing Evidence for Nursing Practice. 9th ed. Philadelphia: Wolters Kluwer Health/Lippincott Williams \& Wilkins, 2012.

18. Kyngäs H, Skaar-Chandler C and Duffy M. The development of instrumental to measure the compliance of adolescents with a chronic disease. J Adv Nurs 2000; 32: 1499-1506.

19. Lunnela J, Kääriäinen $M$ and Kyngäs $H$. Adherence of Finnish people with glaucoma to treatment plans and connected factors. Int J Circumpolar Health. 2011;70: 79-89.

20. Peltonen M, Harald K, Männistö S, et al. National FINRISKI 2007 survey implementing the study and the study results. Publication B34, National Public Health Institute, Department of Health Promotion and Chronic Disease Prevention, Helsinki, Finland, 2008. [in Finnish]. 
21. Zolnierek K and Dimatteo M. Physician communication and patient adherence to treatment: a meta-analysis. Med Care 2009; 47: 826-834.

22. Ens T, Seneviratne C, Jones C, et al. Factors influencing medication adherence in South Asian people with cardiac disorders: an ethnographic study. Int J Nurs Stud 2014; 51: 1472-1481.

23. Schoenthaler A, Kalet A, Nicholson J, et al. Does improving patient-practitioner communication improve clinical outcomes in patients with cardiovascular diseases? A systematic review of the evidence. Patient Educ Couns 2014; 96: 312.

24. Little P, White P, Kelly J, et al. Randomised controlled trial of a brief intervention targeting predominantly non-verbal communication in general practice consultations. Br J Gen Pract 2015; 65: e351-356.

25. Zrinyi $M$ and Horvath $M$. Impact of satisfaction, nurse-patient interactions and perceived benefits on health behaviours following a cardiac event. Eur J Cardiovasc Nurs 2003; 2: 159-166.

26. Robinson J, Callister L, Berry J, et al. Patient-centered care and adherence: definitions and applications to improve outcomes. J Am Acad Nurse Pract 2008; 20: 600-607. 
27. Alm-Roijer C, Stagmo M, Uden G, et al. Better knowledge improves adherence to lifestyle changes and medication in patients with coronary heart disease. Eur J Cardiovasc Nurs 2004; 3: 321-330.

28. Cohen S. Concept analysis of adherence in the context of cardiovascular risk reduction. Nursing Forum 2009; 44: 25-36.

29. Miller T. Health literacy and adherence to medical treatment in chronic and acute illness: A meta-analysis Patient Educ Couns 2016; 99: 1079-1086.

30. Lunnela J, Kääriäinen $M$ and Kyngäs $H$. The views of compliant glaucoma patients on counselling and social support. Scand J Caring Sci 2010; 24: 490498.

31. Oikarinen A, Kääriäinen $M$ and Kyngäs H. A framework for counseling for patients with stroke in nursing: a narrative literature review. J Neurosci Nurs 2014; 46: E3-E14.

32. Adie K and James MA. Does telephone follow-up improve blood pressure after minor stroke or TIA? Age Ageing 2010; 39: 598-603. 


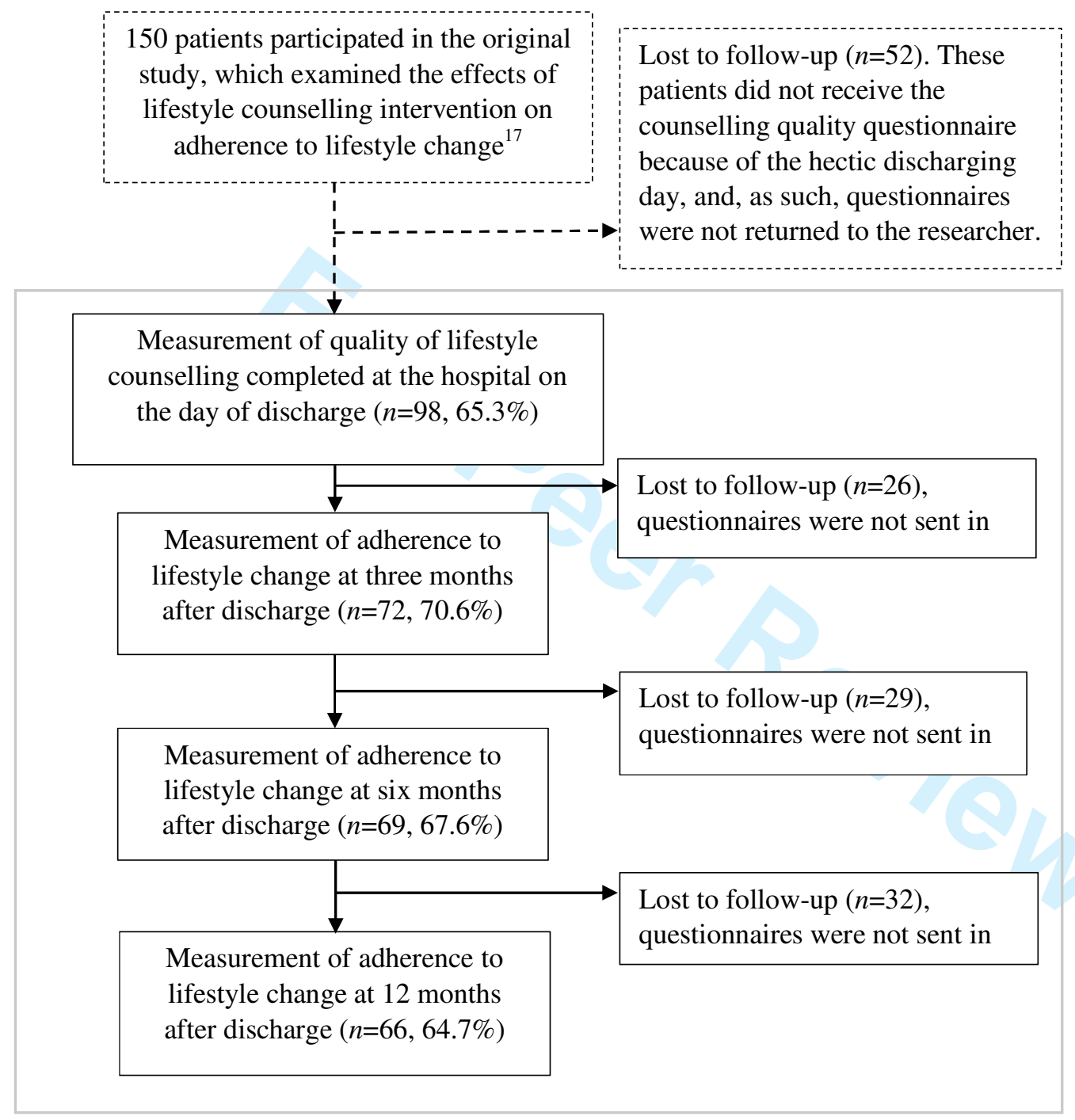

Figure 1. The study design and flow of the participants during the follow-up period 
Table 1. Summated variables created and used in the analysis

\begin{tabular}{lcc}
\hline Summated variable & Number of items & Cronbach's alpha $(\alpha)^{1}$ \\
\hline Adherence to Lifestyle Change Instrument & 4 & 0.81 \\
Alcohol behaviour & 5 & 0.69 \\
Physical activity & 4 & 0.67 \\
Nutritional habits & 3 & 0.74 \\
Adherence to medication & 6 & 0.80 \\
Adherence to lifestyle change & 5 & 0.69 \\
Meaning of lifestyle change & 5 & 0.69 \\
Motivation & 4 & 0.74 \\
Support from family and friends & 2 & 0.96 \\
Support from the doctors at the hospital & 3 & 0.96 \\
Support from the nurses at the hospital & & \\
Counselling Quality Instrument & 10 & 0.88 \\
Counselling resources & 11 & 0.92 \\
Counselling about stroke as an illness and its treatment & 5 & 0.91 \\
Counselling about implications of stroke for everyday life & 9 & 0.90 \\
Counselling about recovery after stroke & 9 & 0.91 \\
Patient-centred counselling & 17 & 0.96 \\
Interactiveness of counselling & 9 & 0.95 \\
Goal-orientation of counselling & 16 & 0.97 \\
Advantages of following the advice given by the counsellor & 1 & - \\
Overall score & & \\
\hline
\end{tabular}

${ }^{1}$ Summated variables were created as a result of factor analysis 


\begin{tabular}{lll} 
Table 2. Background information of the participants $(\mathrm{n}=98)$ & & \\
\hline Variable & $n$ & $\%$ \\
\hline Transient ischemic attack & 41 & 41.8 \\
Stroke & 57 & 58.2 \\
Age & & \\
Gender & & \\
Male & 52 & 53.1 \\
Female & 46 & 46.9 \\
Marital status & & \\
Single & 5 & 5.1 \\
Courtship & 6 & 6.1 \\
Married/cohabitation/domestic partnership & 75 & 76.5 \\
Widowed & 2 & 2.0 \\
Divorced & 10 & 10.2 \\
Education & & \\
Basic education (primary and lower secondary) & 45 & 45.9 \\
Upper secondary education (general or vocational) & 23 & 23.5 \\
Polytechnic or upper vocational diploma & 23 & 23.5 \\
Academic degree & 7 & 7.1 \\
Working status & & \\
Working & 48 & 47.1 \\
Retired & 32 & 31.4 \\
Unemployed or laid-off & 18 & 21.5 \\
\hline
\end{tabular}


Table 3. Significant associations between quality of lifestyle counselling and lifestyle habit variables during the follow-up ( $\mathrm{n}=98$ ).

\begin{tabular}{|c|c|c|c|c|c|c|c|c|c|}
\hline \multirow[t]{2}{*}{ Outcome variables } & \multicolumn{9}{|c|}{ Exploratory variables } \\
\hline & $\begin{array}{l}\text { Counselling } \\
\text { resources }\end{array}$ & $\begin{array}{l}\text { Stroke as } \\
\text { an illness }\end{array}$ & $\begin{array}{l}\text { Implications } \\
\text { for stroke }\end{array}$ & $\begin{array}{l}\text { Recovery } \\
\text { after stroke }\end{array}$ & $\begin{array}{l}\text { Patient- } \\
\text { centeredness }\end{array}$ & Interactiveness & $\begin{array}{l}\text { Goal- } \\
\text { orientation }\end{array}$ & $\begin{array}{l}\text { Advantages of } \\
\text { following advice }\end{array}$ & $\begin{array}{l}\text { Overall } \\
\text { quality score }\end{array}$ \\
\hline \multicolumn{10}{|l|}{ Physical activity $^{1}$} \\
\hline 3 months & $0.29(0.14)^{*}$ & & $0.22(0.09)^{*}$ & & & $0.31(0.10)^{* *}$ & & $0.33(0.11)^{* *}$ & $0.20(0.10)^{*}$ \\
\hline 12 months & - & - & - & - & - & $0.29(0.13)^{*}$ & - & $0.34(0.14)^{*}$ & - \\
\hline \multicolumn{10}{|l|}{ Nutrition $^{1}$} \\
\hline 3 months & - & - & - & - & - & $0.29(0.13)^{*}$ & - & $0.35(0.13)^{*}$ & - \\
\hline 6 months & - & - & - & - & - & $0.29(0.13)^{*}$ & - & $0.30(0.15)^{*}$ & - \\
\hline 12 months & - & - & - & - & - & $0.31(0.12)^{*}$ & - & $0.41(0.14)^{* *}$ & - \\
\hline \multicolumn{10}{|l|}{ Alcohol behaviour } \\
\hline 6 months & - & $0.26(0.13)^{*}$ & - & - & - & - & - & - & - \\
\hline \multicolumn{10}{|l|}{ Adherence to medication ${ }^{1}$} \\
\hline 12 months & $0.66(0.25)^{*}$ & - & - & - & - & - & - & - & - \\
\hline Body mass index ${ }^{1}$ & & & & & & & & & - \\
\hline 3 months & $-0.06(0.02)^{* *}$ & - & - & - & - & - & - & - & - \\
\hline 6 months & $-0.05(0.02)^{*}$ & - & - & - & - & - & - & - & - \\
\hline 12 months & $-0.05(0.02)^{*}$ & - & - & - & - & - & - & - & - \\
\hline \multicolumn{10}{|l|}{ Waist circumference $^{1}$} \\
\hline 3 months & $-0.17(0.07)^{*}$ & - & - & - & - & - & - & - & - \\
\hline Own image of current weight ${ }^{2}$ & & & & & & & - & - & - \\
\hline 12 months & $\begin{array}{c}0.95 \\
(0.92 / 0.98)^{* *}\end{array}$ & $\begin{array}{c}0.96 \\
(0.94 / 0.99)^{*}\end{array}$ & $\begin{array}{c}0.97 \\
(0.95 / 0.99) *\end{array}$ & $\begin{array}{c}0.97 \\
(0.95 / 0.99)^{*}\end{array}$ & $\begin{array}{c}0.97 \\
(0.94 / 0.99)^{* *}\end{array}$ & $\begin{array}{c}0.97 \\
(0.95 / 0.99)^{*}\end{array}$ & - & - & - \\
\hline $\begin{array}{l}\text { Own image of weight change } \\
\text { compared to hospital phase }^{2}\end{array}$ & & & & & & & - & - & - \\
\hline 6 months & & $\begin{array}{c}1.02 \\
(1.00 / 1.05)^{*}\end{array}$ & $\begin{array}{c}1.01 \\
(1.00 / 1.03)^{*}\end{array}$ & & & & $\begin{array}{c}1.02 \\
(1.00 / 1.04)^{*}\end{array}$ & $\begin{array}{c}1.032 \\
(1.00 / 1.05)^{*}\end{array}$ & $\begin{array}{c}1.028 \\
(1.00 / 1.04)^{* *}\end{array}$ \\
\hline
\end{tabular}

$*$ p-value $<0.05 . * *$ p-value $<0.01$

${ }^{1}$ Repeated measures analysis of covariance, slopes and standard deviations presented

${ }^{2}$ Multivariate ordinal logistic regression, odds ratios and $95 \%$ confidence interval presented

Significance, $\mathrm{p}<0.05$

Patients in the follow-up at 3 months $(n=72), 6$ months $(n=69)$ and 12 months $(n=66)$ 
Table 4. Significant associations between quality of lifestyle counselling and factors relating to adherence to lifestyle change variables during the follow-up ( $\mathrm{n}=98$ )

\begin{tabular}{|c|c|c|c|c|c|c|c|c|c|}
\hline \multirow{2}{*}{ Outcome variables } & \multicolumn{9}{|c|}{ Exploratory variables } \\
\hline & $\begin{array}{l}\text { Counselling } \\
\text { resources }\end{array}$ & $\begin{array}{l}\text { Stroke as } \\
\text { an illness }\end{array}$ & $\begin{array}{l}\text { Implications for } \\
\text { stroke }\end{array}$ & $\begin{array}{l}\text { Recovery } \\
\text { after stroke }\end{array}$ & $\begin{array}{l}\text { Patient- } \\
\text { centeredness }\end{array}$ & Interactiveness & $\begin{array}{l}\text { Goal- } \\
\text { orientation }\end{array}$ & $\begin{array}{l}\text { Advantages of } \\
\text { following advice }\end{array}$ & $\begin{array}{l}\text { Overall } \\
\text { quality score }\end{array}$ \\
\hline \multicolumn{10}{|c|}{ Adherence to lifestyle change } \\
\hline 6 months & - & - & - & - & - & - & - & - & $-0.26(0.11)^{*}$ \\
\hline \multicolumn{10}{|l|}{ Motivation } \\
\hline 3 months & - & - & - & - & - & $0.17(0.08)^{*}$ & - & - & - \\
\hline 6 months & $0.34(0.13)^{*}$ & - & - & - & - & - & - & - & - \\
\hline \multicolumn{10}{|c|}{ Importance of lifestyle change } \\
\hline $\begin{array}{l}6 \text { months } \\
\text { Support from the fa }\end{array}$ & - & - & $0.15(0.07)^{*}$ & - & - & - & - & - & - \\
\hline $\begin{array}{l}6 \text { months } \\
\text { Support from the do }\end{array}$ & - & $-0.32(0.13)^{*}$ & $-0.22(0.11)^{*}$ & $-0.40(0.12)^{* *}$ & $-0.27(0.13)^{*}$ & - & $-0.30(0.12)^{*}$ & $-0.36(0.12)^{* *}$ & - \\
\hline $\begin{array}{l}6 \text { months } \\
\text { Support from the nu }\end{array}$ & - & - & - & - & - & $-0.27(0.13)^{*}$ & $-.36(0.13)^{* *}$ & $-0.29(0.14)^{*}$ & $-0.28(0.12)^{*}$ \\
\hline 3 months & $0.69(0.20)^{* *}$ & $0.74(0.15)^{* * *}$ & $0.53(0.12)^{* * *}$ & $0.45(0.15)^{* *}$ & $0.46(0.16)^{* *}$ & $0.42(0.15)^{*}$ & $0.46(0.15)^{* *}$ & $0.44(0.18)^{*}$ & $0.34(0.16)^{*}$ \\
\hline 6 months & $0.77(0.17)^{* * *}$ & $0.67(0.16)^{* * *}$ & $0.39(0.13)^{* *}$ & $0.36(0.17)^{*}$ & - & - & - & $0.36(0.17)^{*}$ & $0.40(0.14)^{* *}$ \\
\hline 12 months & $0.75(0.18)^{* * *}$ & $0.55(0.17)^{* *}$ & $0.44(0.13) * *$ & $0.37(0.16)^{*}$ & $0.45(0.16)^{* *}$ & $0.45(0.15)^{* *}$ & - & - & - \\
\hline
\end{tabular}

Repeated measures analysis of covariance, slopes and standard deviations presented Significance, $\mathrm{p}<0.05$

Patients in the follow-up at 3 months $(n=72), 6$ months $(n=69)$ and 12 months $(n=66)$ 